\title{
AMSSM Position Statement on Cardiovascular Preparticipation Screening in Athletes: Current evidence, knowledge gaps, recommendations and future directions
}

\author{
Jonathan A Drezner, ${ }^{1}$ Francis G $\mathrm{O}^{\prime}$ Connor, ${ }^{2}$ Kimberly G Harmon, ${ }^{1}$ Karl B Fields, ${ }^{3}$ \\ Chad A Asplund, ${ }^{4}$ Irfan M Asif, ${ }^{5}$ David E Price, ${ }^{6}$ Robert J Dimeff, ${ }^{7}$ \\ David T Bernhardt, ${ }^{8}$ William 0 Roberts ${ }^{9}$
}

\begin{abstract}
- Additional material is published online only. To view please visit the journal online (http://dx.doi.org/10.1136/ bjsports-2016-096781).
\end{abstract}

For numbered affiliations see end of article.

\section{Correspondence to} Dr Jonathan A Drezner, Department of Family Medicine, Center for Sports Cardiology, University of Washington, P.O. Box 354060 , Seattle, WA 98195, USA; jdrezner@uw.edu

JAD and FGO cochairs.

Accepted 30 August 2016 Published Online First 22 September 2016

This article has been copublished in the Clinical Journal of Sport Medicine, and Current Sports Medicine Reports.

\section{Linked}

- http://dx.doi.org/10.1136 bisports-2016-096946

- http://dx.doi.org/10.1136/ bjsports-2016-096954

\section{CrossMark}

To cite: Drezner JA, $\mathrm{O}^{\prime}$ Connor FG, Harmon KG, et al. Br I Sports Med 2017:51:153-167.

\section{ABSTRACT}

Cardiovascular screening in young athletes is widely recommended and routinely performed prior to participation in competitive sports. While there is general agreement that early detection of cardiac conditions at risk for sudden cardiac arrest and death (SCA/D) is an important objective, the optimal strategy for cardiovascular screening in athletes remains an issue of considerable debate. At the centre of the controversy is the addition of a resting ECG to the standard preparticipation evaluation using history and physical examination. The American Medical Society for Sports Medicine (AMSSM) formed a task force to address the current evidence and knowledge gaps regarding preparticipation cardiovascular screening in athletes from the perspective of a primary care sports medicine physician. The absence of definitive outcome-based evidence at this time precludes AMSSM from endorsing any single or universal cardiovascular screening strategy for all athletes, including legislative mandates. This statement presents a new paradigm to assist the individual physician in assessing the most appropriate cardiovascular screening strategy unique to their athlete population, community needs and resources. The decision to implement a cardiovascular screening programme, with or without the addition of ECG, necessitates careful consideration of the risk of SCA/D in the targeted population and the availability of cardiology resources and infrastructure. Importantly, it is the individual physician's assessment in the context of an emerging evidence base that the chosen model for early detection of cardiac disorders in the specific population provides greater benefit than harm. AMSSM is committed to advancing evidenced-based research and educational initiatives that will validate and promote the most efficacious strategies to foster safe sport participation and reduce SCA/D in athletes.

\section{BACKGROUND}

Cardiovascular screening in competitive athletes is recommended by most major medical organisations and sports governing bodies; ${ }^{1-6}$ however, agreement on the most appropriate screening protocol remains a topic of considerable controversy. Within the primary care sports medicine and sports cardiology communities, this topic has created a highly charged debate specifically regarding the addition of a resting 12-lead ECG to the preparticipation history and physical examination. This polarised environment has limited a productive discussion of the current evidence, the identification of knowledge gaps and the development of research and educational priorities to improve the cardiovascular care of athletes.

\section{AMSSM charge}

The AMSSM Board of Directors appointed a task force to address the issues surrounding the cardiovascular screening of young competitive athletes (age 12-35) in the USA. The objective of the task force was to examine the current evidence and knowledge gaps relevant to cardiovascular screening in athletes and provide a framework for the AMSSM membership to assess screening recommendations and future research directions. This statement is unique in providing an assessment of cardiovascular screening from the perspective of a primary care sports medicine physician. While it may assist other healthcare professionals with cardiovascular screening in athletes, conclusions may not necessarily apply to physicians from other disciplines.

\section{Writing group selection and process}

The AMSSM President appointed cochairs (JAD and FGO) to assemble a task force to address the topic of cardiovascular preparticipation screening. The task force was carefully selected to include a balanced panel of primary care sports medicine physicians with demonstrated leadership and expertise in athlete cardiovascular screening to represent the different perspectives of cardiovascular preparticipation screening. This panel focused specifically on issues relevant to the potential addition of ECG to the preparticipation physical evaluation (PPE) and did not address the utility of other potential screening modalities, such as echocardiography.

A survey of the task force members was used to identify key discussion areas and generate an initial outline. The panel subsequently engaged in a series of conference calls, literature review and written communications to discuss and analyse specific areas relevant to cardiovascular screening in athletes, followed by an inperson meeting in Atlanta, Georgia, USA, on 21-22 February 2016. An Executive Summary from this panel is presented in box 1 . 


\section{Box 1 Executive summary}

1. The overall role of the preparticipation physical evaluation (PPE) is to evaluate the health of the athlete to optimize safe sports participation.

2. Early detection of athletes at risk for sudden cardiac arrest and death (SCA/D) is an important objective of the PPE for athletes.

3. The primary goal of cardiovascular screening of athletes is to identify underlying cardiac disorders predisposing to SCA/D with the intent to reduce morbidity and mortality by mitigating risk through individualized, patient-centered, and disease-specific medical management.

4. The natural history and absolute risk of conditions associated with SCA/D in athletes identified with a cardiac disorder during screening is largely unknown with limited outcomes-based evidence.

5. Exercise is a known trigger and can unmask occult cardiac disease to precipitate SCA/D.

6. The differential risk of SCA/D between athletes and non-athletes is not fully understood based on current epidemiologic evidence.

7. Athletes display a differential risk for SCA/D based on age, sex, race, sport, and level of play.

8. The current PPE history and physical examination, while pragmatic and widely practiced, is limited in its ability to identify athletes with conditions at risk for SCA/D.

9. The electrocardiogram (ECG) increases early detection of some cardiac disorders associated with SCA/D.

10. ECG interpretation accuracy and reliability are challenges with the principal concern of adding false-positive results to the PPE screening process.

11. Results from centers with considerable experience in athlete ECG screening have demonstrated improved detection of cardiac conditions with potential risk for SCA/ $D$ and decreased false-positive rates.

12. While there is general agreement that early detection of cardiovascular conditions associated with SCA/D in athletes is important, the absence of clear outcomes-based research at this time precludes AMSSM from endorsing a single or universal cardiovascular screening strategy for all athletes.

13. AMSSM supports individual physician autonomy to assess the current evidence and implement the most appropriate cardiovascular screening strategy unique to their athlete population and community resources.

14. Considerations for implementing a cardiovascular screening strategy in a targeted athlete population should include the risk of SCA/D, the available infrastructure and cardiology resources, and the physician assessment that screening for early detection of cardiac disorders has a favorable risk-benefit ratio that will improve athlete outcomes with limited harm.

15. Physicians incorporating ECG in the cardiovascular screening process should optimize strategies to assure accurate ECG interpretation and adequate cardiology resources to conduct the secondary evaluation of ECG abnormalities.

16. No screening program provides absolute protection against SCA/D; an emergency action plan and access to an automated external defibrillator (AED) are essential to improve outcomes from SCA in athletes.

17. AMSSM is committed to evidenced-based research, education, and policy initiatives that will validate and promote the most efficacious strategies to foster safe sport participation and reduce SCA/D in athletes.

\section{THE PPE AND CARDIOVASCULAR SCREENING}

\section{The role and objectives of the PPE}

The overall role of the PPE is to evaluate the health of the athlete to optimise safe sports participation and provide an opportunity to assess current and future health risks and quality of life matters. ${ }^{156}$ Although studies have not shown the PPE to prevent morbidity or mortality in athletes, there is general agreement and acceptance that the primary objective of the PPE is to detect conditions that predispose athletes to serious injury, illness or sudden death. ${ }^{1}$ The current PPE model employs a comprehensive history questionnaire and physical examination. While pragmatic and widely practiced, this model has shown limited effectiveness in screening for conditions associated with sudden death or catastrophic injury. In 2004, an evidence-based review questioned the PPE format as an effective method for health risk screening prior to participation in exercise and sport. ${ }^{7}$ As currently practiced, the PPE may have fallen short of achieving its desired purpose, and its primary goals may need to be re-evaluated and refocused.

Ideally, the PPE is performed in the primary care setting (ie, physician's office) as part of the continuous care of the athlete, creating an entry point for young athletes into the healthcare system and affording opportunities to provide education, counseling and intervention for general wellness and injury prevention. Within this context, screening questionnaires serve as an expanded checklist to guide the physician during the preparticipation evaluation of a young athlete. This panel supports the PPE as a mechanism for the general health assessment of the athlete and to establish a minimum standard to evaluate multiple organ systems that may impact safe sports participation. This panel also supports the development of additional strategies to promote the overall and cardiovascular well-being of young athletes and non-athletes. ${ }^{6}$

\section{The role and objectives of cardiovascular screening}

The primary goal of cardiovascular screening in competitive athletes is to identify underlying cardiac disorders predisposing to sudden cardiac arrest and death $(\mathrm{SCA} / \mathrm{D})$ with the intent to reduce morbidity and mortality by mitigating risk through individualised, patient-centred and disease-specific medical management. ${ }^{2}{ }^{8}$ Cardiovascular screening is one component of a comprehensive PPE, although cardiovascular screening can also be performed independently.

Cardiovascular screening in young athletes is challenging, and all potential screening tools have limitations. This panel proposes that a 'one size fits all' model of cardiovascular screening is not warranted or justified. It is important that the goals and expectations of cardiovascular screening based on history and physical examination alone be re-evaluated and that considerations for more intensive cardiovascular screening be defined. Factors to consider in selecting a cardiovascular screening strategy include: estimates of risk for SCA/D in the individual or athlete population; available sports cardiology resources and expertise; the potential benefits and harms of the screening process and existing sport association directives.

\section{Considerations for the team physician}

Team physicians maintain a unique role and often function as the primary care provider for many of the athletes under their care. Team physicians also recognise that many athletes have a primary care provider, independent of the team, who performs the required PPE and is integral in managing acute and chronic problems that confront the individual athlete. In these 
circumstances, the team physician has the additional challenge and responsibility for shared decision-making, and open communication between the primary care provider, team physician and athlete is essential for optimising care. Furthermore, the PPE and cardiovascular screening protocol implemented by team physicians may be driven by institutional standards or sport governing body requirements.

\section{INCIDENCE OF SCA/D IN YOUNG ATHLETES Current evidence}

Estimates of the rate of SCA/D in athletes vary widely and are affected by study methodology, the means for case identification, age range, the inclusion or exclusion of cardiac arrest with survival and cases occurring at rest or outside of exercise ${ }^{9-21}$ (table 1). Based on available US studies and a systematic review of the literature, a generally accepted annual incidence of all SCA/D is $\sim 1$ in 80000 in high school athletes and 1 in 50000 in college athletes. ${ }^{22}$ Studies indicate that $56-80 \%$ of SCA/D in young athletes occurs during exercise with the remainder considered nonexertional (ie, at rest or during sleep). ${ }^{12} 1721$

Evidence supports that athletes display a differential risk for SCA/D based on age, sex, race, sport and level of play. ${ }^{9} 10$ 14-21 Incident rates are consistently higher in male and AfricanAmerican athletes. Male college basketball players have the highest reported overall risk of sudden cardiac death (SCD) at 1 in 9000 per year, and male African-American college athletes have a reported SCD risk of 1 in 16000 per year. ${ }^{21}$ In addition, studies consistently report that two sports alone, male basketball and football, account for $50-61 \%$ of all identified cases of SCA/ D. ${ }^{12} 17{ }^{21}$ Studies with mandatory reporting systems in other active young adult populations, such as military personnel and firefighters, have demonstrated comparable rates of SCA/D as in college male athletes. ${ }^{23-25}$

\section{Knowledge gaps}

Without a mandatory reporting system for SCA/D in athletes, cases may go undetected and current incidence estimates may not represent the true risk. In addition, current epidemiological studies do not provide a complete understanding of the comparative risk of SCA/D in athletes versus non-athletes as the estimated incidence range of SCA/D in the general population of adolescents and young adults overlaps with that of SCA/D in adolescent and young adult athletes ${ }^{18}{ }^{25-29}$ (table 1). In a prospective study monitoring SCA in US high schools, student athletes were 3.6 times more likely to suffer SCA while on school campus than non-athlete peers. ${ }^{18}$ However, this study did not account for activities off campus and did not allow an absolute risk comparison between the groups. In contrast, a recent retrospective study comparing the risk of SCD in adolescent and young adult athletes versus non-athletes from Hennepin County, Minnesota, found a higher incidence of sudden cardiovascularrelated death in non-athletes. ${ }^{30}$ This study was limited by estimates of the athlete and non-athlete populations at risk and by unclear methodology to confirm if cases participated in an organised sport.

Overall, definitive evidence that US athletes as a whole are at higher risk of SCA/D than the general population of similar age is lacking. This uncertainty has generated ethical concerns about limiting a screening programme for unsuspected genetic and/or congenital heart disorders to only competitive athletes. ${ }^{30} 31$ However, systematic preparticipation screening is currently required by sports governing bodies for high school, college and professional athletes in the USA, and there is substantial evidence that some athlete groups, especially in the college age range, have higher rates of SCA/D than estimates for the general population. A standardised approach to the evaluation and reporting of SCA/D in athletes has been proposed and may lead to more precise data moving forward. ${ }^{32}$

\section{PREVALENCE OF DISORDERS ASSOCIATED WITH SCD Current evidence}

Exercise is a known trigger and can unmask occult cardiac disease to precipitate SCA/D. ${ }^{33}$ The prevalence of cardiac conditions associated with SCA/D in young athletes is $\sim 0.3 \%{ }^{2}$ This estimate is supported by multiple studies using non-invasive cardiac evaluation tools to identify cardiac disorders at potential risk of SCA/D in young athletes. ${ }^{34-41}$ The most commonly reported causes of SCA/D in athletes include hypertrophic cardiomyopathy, anomalous coronary arteries, idiopathic left ventricular hypertrophy, arrhythmogenic right ventricular cardiomyopathy, dilated cardiomyopathy, myocarditis, long QT syndrome, ventricular pre-excitation/Wolff-Parkinson-White, aortic dissection and atherosclerotic coronary artery disease. ${ }^{12} 2142-45$ Notably, up to $44 \%$ of athletes with SCD have no structural cardiac abnormalities identified on postmortem examination. ${ }^{21}{ }^{43-47}$ These cases, known as autopsy-negative sudden unexplained death, may be due to primary electrical diseases and inherited arrhythmia syndromes. Structurally normal hearts are also reported in up to $41 \%$ of active military personnel with non-traumatic sudden death ${ }^{23} 24$ (table 2).

Hypertrophic cardiomyopathy represents $8-36 \%$ of cases in US athletes depending on the study. ${ }^{12}{ }^{21}$ While the reported prevalence of hypertrophic cardiomyopathy in the general adult population is 1 in 500 or possibly higher, ${ }^{4-50}$ studies in young athletes have not identified a similar prevalence. This is perhaps due to variable morphological expression of hypertrophic cardiomyopathy during adolescence and young adulthood or functional limitations leading to self-selection out of competitive sports. Based on existing studies, the detected prevalence of hypertrophic cardiomyopathy in a young athletic population is $\sim 1$ in 800 to 1 in $2600 .^{38} 4151-54$ Atherosclerotic coronary artery disease as a cause of SCA/D in athletes increases with age and is also the most common identified cause of SCD in studies of the general population under age $35 .{ }^{29} 55-59$

\section{Knowledge gaps}

The lack of standardised autopsy protocols and wider expertise in forensic cardiovascular pathology present challenges to a more precise understanding of the aetiology of SCA/D in athletes. However, even with such protocols, many of these conditions remain challenging to diagnose at autopsy. Current data sets largely involve review of autopsy results that may be limited by inadequate quality or information. In cases with negative or borderline autopsy findings, postmortem genetic testing for cardiovascular conditions with known genetic mutations may provide additional insights into the causes of SCA/D. ${ }^{60} 61$

A better understanding of the prevalence and natural history of conditions leading to $\mathrm{SCA} / \mathrm{D}$ in different athlete populations will help predict the frequency of screening abnormalities and the potential value of different screening modalities. In addition, while high-risk features for some cardiovascular disorders have been defined, a number of detectable conditions present an uncertain risk of SCA/D in athletes. More information is needed to fully understand which conditions or subsets of conditions will most likely lead to SCA/D. 


\begin{tabular}{|c|c|c|c|c|c|c|c|c|}
\hline Study & $\begin{array}{l}\text { Study design and } \\
\text { population }\end{array}$ & Case identification & Denominator & $\begin{array}{l}\text { Exertional SCD or all } \\
\text { SCD? }\end{array}$ & $\begin{array}{l}\text { SCD or } \\
\text { all } \\
\text { SCA/D? }\end{array}$ & $\begin{array}{l}\text { Study } \\
\text { years }\end{array}$ & $\begin{array}{l}\text { Age range; } \\
\text { number of } \\
\text { cases }\end{array}$ & Annual incidence \\
\hline \multicolumn{9}{|l|}{ Athletes } \\
\hline Van Camp et $a l^{9}$ & $\begin{array}{l}\text { Retrospective cohort; high } \\
\text { school and college athletes }\end{array}$ & $\begin{array}{l}\text { National Center for Catastrophic } \\
\text { Sports Injury Research and Media } \\
\text { Reports }\end{array}$ & $\begin{array}{l}\text { Data from NCAA, NFHS, NAIA and NJCAA, } \\
\text { added together with conversion factor ( } 1.9 \\
\text { for high school and } 1.2 \text { for college) used to } \\
\text { account for multisport athletes 'based on } \\
\text { discussions with representatives from the } \\
\text { national organisations'. }\end{array}$ & Exertional & SCD & $\begin{array}{l}1983- \\
1993\end{array}$ & $\begin{array}{l}13-24 ; \\
N=160\end{array}$ & $\begin{array}{l}\text { College }+ \text { High School } \\
\text { Overall 1:188 000 } \\
\text { Male 1:134000 } \\
\text { Female 1:752000 } \\
\text { High school } \\
\text { Overall 1:213000 } \\
\text { Male 1:152 000 } \\
\text { Female 1:861 } 000 \\
\text { College } \\
\text { Overall 1:94 } 000 \\
\text { Male 1:69 000 } \\
\text { Female 1:356 } 000\end{array}$ \\
\hline Maron et $a l^{10}$ & $\begin{array}{l}\text { Retrospective cohort; } \\
\text { Minnesota high school } \\
\text { athletes }\end{array}$ & Catastrophic insurance claims & $\begin{array}{l}\text { Minnesota State High School League } \\
\text { (estimated using conversion factor of } 2.3 \text { to } \\
\text { account for multisport athletes) }\end{array}$ & $\begin{array}{l}\text { Exertional only during } \\
\text { school sponsored } \\
\text { sport }\end{array}$ & SCD & $\begin{array}{l}1985- \\
1997\end{array}$ & $16-17 ; N=3$ & $\begin{array}{l}\text { High school } \\
\text { Overall 1:217 } 000 \\
\text { Male 1:129 } 000 \\
\text { Female } 0\end{array}$ \\
\hline Drezner et al/11 & $\begin{array}{l}\text { Retrospective survey; college } \\
\text { athletes }\end{array}$ & $\begin{array}{l}\text { Survey of NCAA Division I } \\
\text { institutions (244/326 responded) }\end{array}$ & Reported number of athletes & All & SCD & - & $\mathrm{N}=5$ & $\begin{array}{l}\text { College } \\
\text { Overall 1:67 } 000\end{array}$ \\
\hline Maron et $a l^{12}$ & $\begin{array}{l}\text { Retrospective cohort; } \\
\text { amateur and competitive } \\
\text { athletes }\end{array}$ & $\begin{array}{l}\text { US Registry for Sudden Death in } \\
\text { Athletes }\end{array}$ & $\begin{array}{l}\text { An estimated } 10.7 \text { million participants per } \\
\text { year } \leq 39 \text { years of age in all organised } \\
\text { amateur and competitive sports }\end{array}$ & All & $\begin{array}{l}\text { SCA } \\
+\mathrm{SCD}\end{array}$ & $\begin{array}{l}1980- \\
2006\end{array}$ & $\begin{array}{l}8-39 ; \\
N=1046\end{array}$ & $\begin{array}{l}\text { All athletes } \\
\text { 1:164 } 000\end{array}$ \\
\hline Drezner et al ${ }^{13}$ & $\begin{array}{l}\text { Cross-sectional survey; high } \\
\text { school athletes }\end{array}$ & $\begin{array}{l}\text { Survey of } 1710 \text { high schools with } \\
\text { AEDs }\end{array}$ & Reported number of student athletes & $\begin{array}{l}\text { All cases occurring on } \\
\text { campus }\end{array}$ & $\begin{array}{l}\text { SCA } \\
+\mathrm{SCD}\end{array}$ & $\begin{array}{l}2006- \\
2007\end{array}$ & $\begin{array}{l}14-17 \\
N=14\end{array}$ & $\begin{array}{l}\text { High school } \\
1: 23000 \text { (SCA+SCD) } \\
1: 64000 \text { (SCD) }\end{array}$ \\
\hline Harmon et al/4 & $\begin{array}{l}\text { Retrospective cohort; college } \\
\text { athletes }\end{array}$ & $\begin{array}{l}\text { Parent Heart Watch database, } \\
\text { NCAA Resolutions list, } \\
\text { catastrophic insurance claims }\end{array}$ & Participation data from the NCAA & All & SCD & $\begin{array}{l}2004- \\
2008\end{array}$ & $\begin{array}{l}18-26 \\
N=37\end{array}$ & $\begin{array}{l}\text { College } \\
\text { Overall 1:43000 } \\
\text { Male 1:33 } 000 \\
\text { Female 1:76000 } \\
\text { Black 1:17000 } \\
\text { White 1:58 000 } \\
\text { Male, black 1:13000 } \\
\text { Male, basketball 1:7000 } \\
\text { Male, Division I basketball } \\
\text { 1:3000 }\end{array}$ \\
\hline Maron et $a l^{15}$ & $\begin{array}{l}\text { Retrospective cohort; } \\
\text { Minnesota high school } \\
\text { athletes }\end{array}$ & $\begin{array}{l}\text { US Registry for Sudden Death in } \\
\text { Athletes }\end{array}$ & $\begin{array}{l}\text { Minnesota State High School League statistics } \\
\text { (estimated using conversion factor of } 2.3 \text { to } \\
\text { account for multisport athletes) }\end{array}$ & All & $S C D$ & $\begin{array}{l}1986- \\
2011\end{array}$ & $\begin{array}{l}12-18 \\
N=13\end{array}$ & $\begin{array}{l}\text { High school } \\
\text { Overall 1:150 } 000 \\
\text { Male 1:83000 } \\
\text { Female } 0\end{array}$ \\
\hline Roberts and Stovitz ${ }^{16}$ & $\begin{array}{l}\text { Retrospective cohort; } \\
\text { Minnesota high school } \\
\text { athletes }\end{array}$ & Catastrophic insurance claims & $\begin{array}{l}\text { Minnesota State High School League statistics } \\
\text { (sum of unduplicated athletes 1993-1994 } \\
\text { through 2011-2012 school years) }\end{array}$ & $\begin{array}{l}\text { Exertional only during } \\
\text { school sponsored } \\
\text { sport }\end{array}$ & $S C D$ & $\begin{array}{l}1993- \\
2012\end{array}$ & $12-19 ; N=4$ & $\begin{array}{l}\text { High school } \\
\text { 1:417 } 000(1993-2012) \\
\text { 1:909 } 000(2003-2012) \\
\text { Female } 0\end{array}$ \\
\hline Maron et $a l^{17}$ & $\begin{array}{l}\text { Retrospective cohort; college } \\
\text { athletes }\end{array}$ & & Participation data from the NCAA & All & $S C D$ & $\begin{array}{l}2002- \\
2011\end{array}$ & $\begin{array}{l}17-26 \\
N=64\end{array}$ & $\begin{array}{l}\text { College } \\
\text { Overall 1:63000 }\end{array}$ \\
\hline
\end{tabular}




\begin{tabular}{|c|c|c|c|c|c|c|c|c|}
\hline Study & $\begin{array}{l}\text { Study design and } \\
\text { population }\end{array}$ & Case identification & Denominator & $\begin{array}{l}\text { Exertional SCD or all } \\
\text { SCD? }\end{array}$ & $\begin{array}{l}\text { SCD or } \\
\text { all } \\
\text { SCA/D? }\end{array}$ & $\begin{array}{l}\text { Study } \\
\text { years }\end{array}$ & $\begin{array}{l}\text { Age range; } \\
\text { number of } \\
\text { cases }\end{array}$ & Annual incidence \\
\hline & & $\begin{array}{l}\text { US Registry for Sudden Death in } \\
\text { Athletes and NCAA resolutions } \\
\text { list }\end{array}$ & & & & & & $\begin{array}{l}\text { Male 1:56000 } \\
\text { Female 1:333000 } \\
\text { Black 1:26000 } \\
\text { White 1:143000 }\end{array}$ \\
\hline Toresdahl et al ${ }^{18}$ & $\begin{array}{l}\text { Prospective observational; } \\
\text { high school students and } \\
\text { student athletes }\end{array}$ & $\begin{array}{l}2149 \text { high schools monitored for } \\
\text { SCA events on school campus }\end{array}$ & $\begin{array}{l}\text { Reported number of students and student } \\
\text { athletes }\end{array}$ & $\begin{array}{l}\text { All cases occurring on } \\
\text { school campus }\end{array}$ & $\begin{array}{l}\text { SCA } \\
+ \text { SCD }\end{array}$ & $\begin{array}{l}2009- \\
2011\end{array}$ & $\begin{array}{l}14-18 \\
N=44\end{array}$ & $\begin{array}{l}\text { Student non-athlete } \\
\text { Overall 1:326 } 000 \\
\text { Male 1:286000 } \\
\text { Female 1:357 } 000\end{array}$ \\
\hline & & & & & & & & $\begin{array}{l}\text { Student athlete } \\
\text { Overall 1:88 000 } \\
\text { Male 1:58 000 } \\
\text { Female 1:323000 }\end{array}$ \\
\hline Drezner et al ${ }^{19}$ & $\begin{array}{l}\text { Retrospective cohort; } \\
\text { Minnesota high school } \\
\text { athletes }\end{array}$ & Public media reports & $\begin{array}{l}\text { Minnesota State High School League statistics } \\
\text { (sum of unduplicated athletes 2003-2004 } \\
\text { through 2011-2012 school years) }\end{array}$ & All & $\begin{array}{l}\text { SCA } \\
+\mathrm{SCD}\end{array}$ & $\begin{array}{l}2003- \\
2012\end{array}$ & $\begin{array}{l}14-18 \\
N=13\end{array}$ & $\begin{array}{l}\text { High school } \\
\text { Overall 1:71 } 000 \\
\text { Female 0 } \\
\text { Male, basketball 1:21 } 000\end{array}$ \\
\hline Harmon et $a l^{20}$ & $\begin{array}{l}\text { Retrospective cohort; high } \\
\text { school athletes from seven } \\
\text { states }\end{array}$ & Public media reports & Participation data from the NFHS & All & $\begin{array}{l}\text { SCA } \\
+ \text { SCD }\end{array}$ & $\begin{array}{l}2007- \\
2013\end{array}$ & $\begin{array}{l}14-18 \\
N=109\end{array}$ & $\begin{array}{l}\text { High school } \\
\text { Overall 1:67 } 000 \\
\text { Male 1:45000 } \\
\text { Female 1:238 000 } \\
\text { Male, basketball 1:37 } 000\end{array}$ \\
\hline Harmon et $a l^{21}$ & $\begin{array}{l}\text { Retrospective cohort; college } \\
\text { athletes }\end{array}$ & $\begin{array}{l}\text { Parent Heart Watch database, } \\
\text { NCAA resolutions list, } \\
\text { catastrophic insurance claims }\end{array}$ & Participation data from the NCAA & All & SCD & $\begin{array}{l}2003- \\
2013\end{array}$ & $\begin{array}{l}17-26 \\
N=79\end{array}$ & $\begin{array}{l}\text { College } \\
\text { Overall 1:53 } 000 \\
\text { Male 1:38 } 000 \\
\text { Female 1:122 } 000 \\
\text { Black 1:21000 } \\
\text { White 1:68 } 000 \\
\text { Football 1:36 000 } \\
\text { Male, soccer 1:24 000 } \\
\text { Male, black 1:16000 } \\
\text { Male, basketball 1:9000 } \\
\text { Male, black, basketball } \\
\text { 1:5300 } \\
\text { Male, Div. I basketball } \\
\text { 1:5200 }\end{array}$ \\
\hline \multicolumn{9}{|l|}{ Military } \\
\hline Eckart et al ${ }^{23}$ & $\begin{array}{l}\text { Retrospective cohort; military } \\
\text { recruits }\end{array}$ & $\begin{array}{l}\text { Mandatory reporting of all } \\
\text { deaths to the Department of } \\
\text { Defense registry with autopsy } \\
\text { data }\end{array}$ & Department of Defense & All & SCD & $\begin{array}{l}1977- \\
2001\end{array}$ & $\begin{array}{l}18-35 \\
\mathrm{~N}=108\end{array}$ & $\begin{array}{l}\text { Military recruits } \\
\text { 1:15 } 000 \text { (cardiac) } \\
\text { 1:9000 (cardiac+idiopathic) }\end{array}$ \\
\hline Eckart et al ${ }^{24}$ & $\begin{array}{l}\text { Retrospective cohort; active } \\
\text { military personnel }\end{array}$ & $\begin{array}{l}\text { Mandatory reporting of all } \\
\text { deaths to the Department of } \\
\text { Defense registry with autopsy } \\
\text { data }\end{array}$ & Department of Defense statistics & All & SCD & $\begin{array}{l}1998- \\
2008\end{array}$ & $\begin{array}{l}18-35 \\
N=298\end{array}$ & $\begin{array}{l}\text { Military personnel } \\
\text { Male } \\
\text { Age }<20 \text { 1:30 000 } \\
20-24 \text { 1:41 } 000 \\
25-291: 30000 \\
30-35 \text { 1:25 000 }\end{array}$ \\
\hline
\end{tabular}


Table 1 Continued

\begin{tabular}{|c|c|c|c|c|c|c|c|}
\hline Study & $\begin{array}{l}\text { Study design and } \\
\text { population }\end{array}$ & Case identification & Denominator & $\begin{array}{l}\text { Exertional SCD or all } \\
\text { SCD? }\end{array}$ & $\begin{array}{l}\text { SCD or } \\
\text { all } \\
\text { SCA/D? }\end{array}$ & $\begin{array}{l}\text { Study } \\
\text { years }\end{array}$ & $\begin{array}{l}\text { Age range; } \\
\text { number of } \\
\text { cases }\end{array}$ \\
\hline
\end{tabular}

\begin{tabular}{|c|c|c|c|c|c|c|c|c|}
\hline & & & & & & & & $\begin{array}{l}\text { Female } \\
\text { Age <20 120000 } \\
20-241: 92000 \\
25-291: 161000 \\
30-351: 147000\end{array}$ \\
\hline \multicolumn{9}{|c|}{ General population } \\
\hline Atkins et $a l^{26}$ & $\begin{array}{l}\text { Prospective population } \\
\text { cohort study }\end{array}$ & $\begin{array}{l}\text { EMS database of out-of-hospital } \\
\text { cardiac arrest }\end{array}$ & Population statistics & All & $\begin{array}{l}\text { SCA } \\
+S C D\end{array}$ & $\begin{array}{l}2005- \\
2007\end{array}$ & $\begin{array}{l}12-19 ; \\
N=114\end{array}$ & 1:27 000 \\
\hline Chugh et $a l^{27}$ & Prospective population based & $\begin{array}{l}\text { Data from EMS, medical } \\
\text { examiner and area hospitals }\end{array}$ & $\begin{array}{l}\text { Population statistics from Multnomah County, } \\
\text { Oregon }\end{array}$ & All & $\begin{array}{l}\text { SCA } \\
+ \text { SCD }\end{array}$ & $\begin{array}{l}2002- \\
2005\end{array}$ & $10-14 ; N=2$ & 1:59 000 \\
\hline Cooper et a $\left.\right|^{28}$ & Retrospective cohort & $\begin{array}{l}\text { Automated data from four health } \\
\text { plans }\end{array}$ & Computerised health records & All & $\begin{array}{l}\text { SCA } \\
+ \text { SCD }\end{array}$ & $\begin{array}{l}1986- \\
2005\end{array}$ & $2-24 ; N=33$ & 1:78 000 \\
\hline Meyer et al ${ }^{29}$ & Prospective population based & $\begin{array}{l}\text { EMS cardiac arrest database over } \\
30 \text { years }\end{array}$ & $\begin{array}{l}\text { Population statistics from King County, } \\
\text { Washington }\end{array}$ & All & $\begin{array}{l}\text { SCA } \\
+ \text { SCD }\end{array}$ & $\begin{array}{l}1980- \\
2009\end{array}$ & $\begin{array}{l}14-35 \\
N=305\end{array}$ & $\begin{array}{l}\text { Age 14-24 1:69000 } \\
\text { Age 25-35 1:23000 }\end{array}$ \\
\hline Farioli et $a l^{25}$ & Retrospective cohort & $\begin{array}{l}\text { US Fire Administration and the } \\
\text { National Institute for } \\
\text { Occupational Safety and Health } \\
\text { Fire Fighter Fatality Investigation } \\
\text { and Prevention Program }\end{array}$ & $\begin{array}{l}\text { Current population survey of the number of } \\
\text { US career firefighters }\end{array}$ & All & SCD & $\begin{array}{l}1998- \\
2012\end{array}$ & $\begin{array}{l}18-34 ; \\
\mathrm{N}=14\end{array}$ & $\begin{array}{l}\text { Age 18-24 1:19000 } \\
\text { Age 25-34 1:26000 }\end{array}$ \\
\hline Maron et $a \beta^{30}$ & Retrospective cohort & Records of the Medical Examiner & $\begin{array}{l}\text { Data from the Minnesota Department of } \\
\text { Education, National Center for Education } \\
\text { Statistics and the Minnesota State High } \\
\text { School League for Hennepin County, } \\
\text { Minnesota }\end{array}$ & All & SCD & $\begin{array}{l}2000- \\
2014\end{array}$ & $\begin{array}{l}14-23 ; \\
N=27\end{array}$ & $\begin{array}{l}\text { Non-athlete } \\
\text { 1:39000 } \\
\text { Athlete } \\
\text { 1:121 } 000\end{array}$ \\
\hline
\end{tabular}

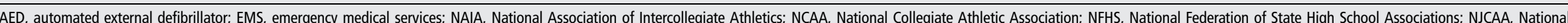
Junior College Athletic Association; SCAID, sudden cardiac arrest and death; SCA, sudden cardiac arrest; SCD, sudden cardiac death. 
Table 2 Causes of sudden cardiac death in athletes, military personnel and the young general population

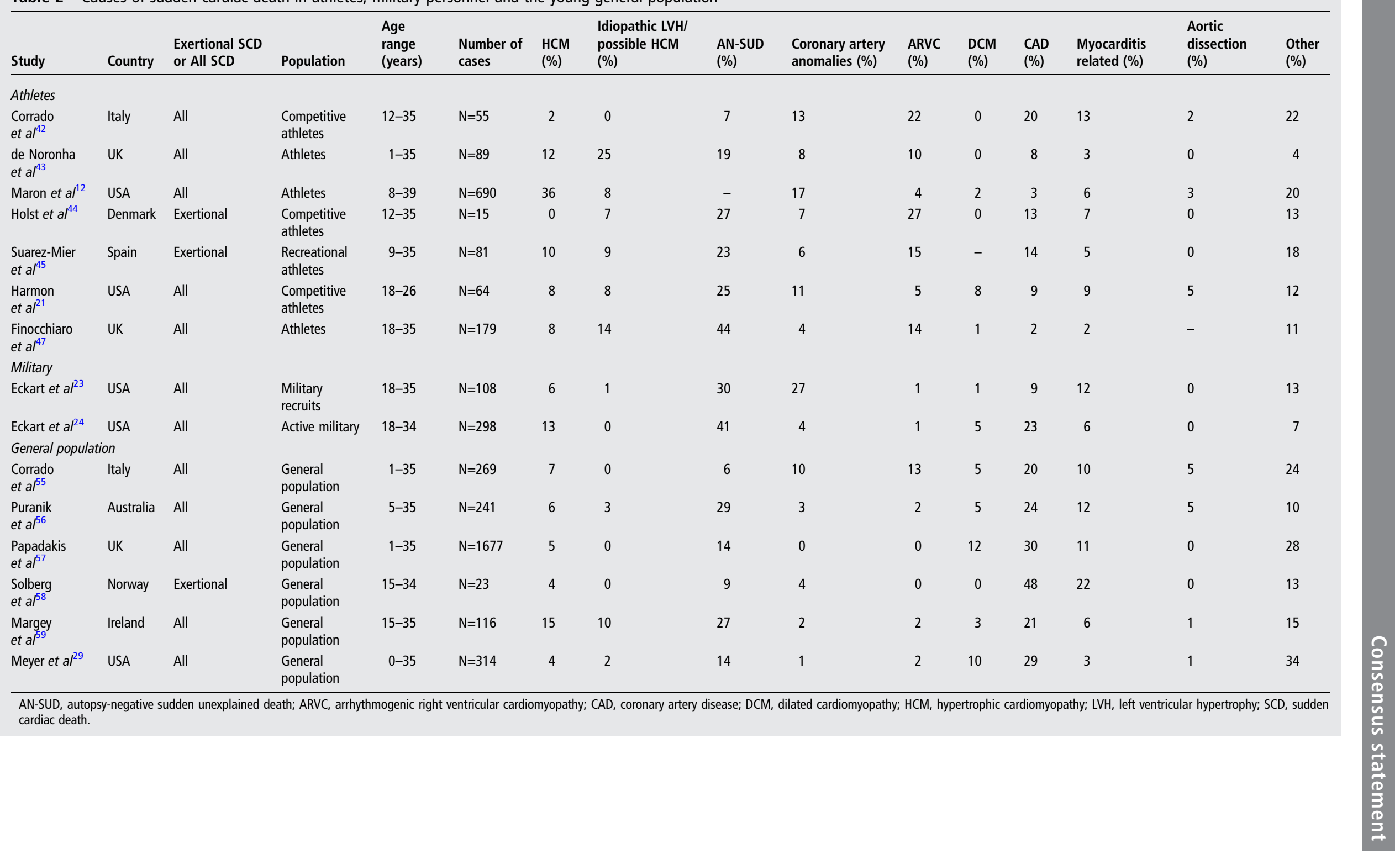

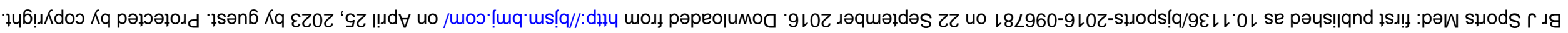




\section{CARDIOVASCULAR SCREENING IN ATHLETES Current assessment}

History and physical examination has been the traditional standard for cardiovascular preparticipation screening in the USA. $^{1} 26263$ The addition of a screening ECG has potential benefits and potential risks. Regardless of the screening strategy, the optimal age and frequency to conduct cardiovascular screening in athletes is uncertain, but generally begun between the ages of 12 and 14 and repeated every 1-3 years. Ideally, preparticipation cardiovascular screening should take place with adequate time prior to the start of a sports season to perform secondary testing of screening abnormalities.

\section{HISTORY AND PHYSICAL EXAMINATION FOR THE CARDIOVASCULAR SCREENING OF ATHLETES Benefits}

Identifying athletes with potential cardiovascular symptoms (ie, exertional syncope) or a family history of juvenile/young adult SCA/D or inheritable cardiac conditions are important elements of screening. The history and physical examination is a core skill routinely practised by medical providers and a fundamental component of the PPE. Based on existing studies, the sensitivity of history and physical examination for the detection of cardiac disorders with elevated risk for SCA/D is $\sim 20 \%,{ }^{54}$ representing a small but important group of athletes potentially identifiable by the customary screening model. A screening examination also can identify previously unrecognised hypertension in adolescent and young adult athletes, which is important in the prevention of long-term cardiovascular morbidity. ${ }^{64-66}$

\section{Limitations}

Approximately $80 \%$ of athletes who suffer SCA/D have no documented warning symptoms at the time of PPE screening and may be missed by an evaluation focused primarily on signs and symptoms. ${ }^{47}$ 67-69 Standardised symptom and family history questionnaires, such as the PPE Monograph and American Heart Association questions, also demonstrate a high positive response rate in high school (15-31\%) and college (27$37 \%$ ) athletes, ${ }^{40} 4170-72$ requiring the medical provider to understand the purpose of the questions and the requisite pursuit of additional history to determine the need for secondary testing. Variable understanding of the PPE questions and process can create wide variation in provider follow-up and limit the effectiveness of standardised history questionnaires as a screening tool.

To be effective, PPE questionnaires require an honest patient and thus may fail to elicit a positive response to symptoms that are present but not volunteered. In addition, cardiovascular symptoms may be present in athletes with occult disorders, but misinterpreted as a normal response to vigorous exertion. Some athletes also may develop symptoms subsequent to the PPE, and thus a cardiac disorder could be missed by an evaluation performed at a single time point. Part of the PPE process should include athlete and family education on cardiovascular signs and symptoms that may develop after the examination and warrant re-evaluation.

Several studies indicate that the PPE is not implemented adequately or uniformly. ${ }^{73-76}$ This incomplete compliance and awareness of expert guidelines complicates our understanding of the potential benefit and overall feasibility of implementing systematic questionnaires as a primary screening strategy. Recent studies suggest that less than half of primary care physicians are aware of the cardiovascular screening recommendations from the American Heart Association or the PPE Monograph. ${ }^{73} 74$ In a survey of cardiovascular screening practices at National Collegiate Athletic Association Division I universities, 92\% of responding universities did not use PPE forms that fully meet the American Heart Association recommendations for cardiovascular screening, ${ }^{75}$ and, in 2014 , only $43 \%$ of state high school athletic associations require forms that fully address all of the PPE Monograph (4th edition) personal and family history cardiovascular screening recommendations. ${ }^{76}$

Physical examination also presents challenges as a screening tool for the identification of cardiovascular disorders. Clinical agreement during cardiac auscultation can vary widely among medical providers, and the ability to distinguish physiological from pathological murmurs is difficult even among experts. ${ }^{77-81}$ In one pilot study evaluating auscultation clinical agreement during a preparticipation assessment of 101 consecutive athletes, two board certified family physicians each identified six individuals requiring further investigation, but only agreed on one, demonstrating limited agreement with a $\kappa$ of $0.114(95 \%$ CI -0.182 to 0.411$).{ }^{81}$ Identification and clinical agreement of the physical stigmata of Marfan's syndrome and related connective tissue disorders is also challenging for primary care providers and experts. ${ }^{82}$

\section{Knowledge gaps}

Despite its use and existence for over two decades, the immediate-term and long-term outcomes of the customary PPE are largely unknown. In fact, no study, to date, has tested the ability of modern recommendations for cardiovascular screening by history and physical examination alone to detect cardiovascular conditions that pose potential risk of SCA/D in athletes. Current estimates of the sensitivity of the history and physical examination are extrapolated from studies that also use other screening modalities such as ECG, and thus interpretation of history or physical examination findings may be confounded when viewed in the context of a normal or abnormal ECG. Thus, the extent to which a screening evaluation using only history and physical examination can identify athletes with conditions associated with elevated risk of SCA/D is yet to be clearly established.

The potential benefit of education, continuity and repeat assessments using a cardiac history and physical examination also requires additional investigation. Further research is needed to improve the sensitivity, specificity, positive predictive value and reliability of screening questions and the physical examination for the identification of athletes with at risk disorders. The physician response to positive history questions remains relatively uninvestigated and non-uniform, and more research is needed to determine the clinical features and pathways for additional evaluation in athletes. Electronic PPE formats may provide a platform to better understand the current PPE process and improve question sets. Whether a PPE performs more effectively than an annual health examination with the patient's primary care physician is also unknown.

\section{ECG FOR THE CARDIOVASCULAR SCREENING OF ATHLETES Benefits}

The addition of a screening ECG to the history and physical examination increases the detection of cardiac disorders potentially at risk of SCA/D in athletes. ${ }^{39-415468707283} \mathrm{An}$ estimated $60 \%$ of the disorders associated with SCA/D in young individuals may have detectable ECG abnormalities. ${ }^{17}$ In studies conducted by centres with considerable experience in ECG screening, adding an ECG demonstrates improved 
sensitivity compared to history and physical examination in detecting previously undiagnosed and unsuspected cardiac disorders. $^{34-4151708384}$

ECG is an objective test, but subject to variable interpretation. The use of modern ECG interpretation guidelines that account for physiological adaptations in athletes have reduced the falsepositive burden without a demonstrable change in sensitivity. ${ }^{84-87}$ False-positive rates have declined, ranging from $2.5 \%$ to $6.6 \%$, when ECG review is conducted by clinicians experienced in applying modern interpretation standards. $4041707283-88$

An ECG deemed to be abnormal is typically an actionable finding in the screening evaluation of athletes. An abnormal ECG also may raise awareness to vague symptoms or relevant family history that previously went unreported or uninvestigated, or initiate a more indepth assessment of questionable physical examination findings.

\section{Limitations}

ECG interpretation in athletes is challenging even when using modern criteria, and clinical agreement and reproducibility between physicians can be limited. Some studies have demonstrated that systematic evaluation of an athlete's ECG using standardised criteria improves interpretation accuracy. ${ }^{89} 90$ However, interobserver variability and the reliability of ECG standards even among experienced physicians remains a major concern. ${ }^{9192}$ In one study, paediatric cardiologists, without the use of a standardised criteria set, achieved a sensitivity of $68 \%$ and a specificity of $70 \%$ for recognition of abnormal ECG patterns that occur infrequently, but may represent conditions predisposing to SCD. ${ }^{93}$

The false-positive rate for ECG screening is strongly associated with the criteria used to guide interpretation and the experience of the interpreting physician. ${ }^{83-87} \mathrm{~A}$ false-positive ECG leads to additional testing that increases the total cost and may pose other risks to the athlete depending on the nature and timing of the test. ECG is not $100 \%$ sensitive for ECG detectable disorders (false-negatives), and the age at which some cardiac disorders manifest ECG abnormalities is variable, raising concerns about the timing of testing and requirements for repeat testing. In addition, some conditions at risk for SCA/D do not manifest ECG abnormalities and thus would not be detectable through ECG screening. Finally, like history and physical examination, some conditions that create an increased risk for SCA/D are sporadic and not present at the time the ECG is obtained.

Physician training and experience are linked to accurate ECG interpretation and limit the ability of many physicians to add ECG to the current screening process. In addition, technical standards need to be adhered to as the use of poor quality, lowresolution ECG instruments or improper recording techniques can also produce misleading results. ${ }^{94}$ Physician infrastructure and resources remain major obstacles to considering quality application of ECG in the cardiovascular preparticipation evaluation of athletes. ${ }^{95}$

\section{Knowledge gaps}

Education in ECG interpretation is a critical step that should be accomplished before including an ECG in the athlete cardiovascular screening process. While educational modules have been developed, the impact and effectiveness of ECG interpretation training programmes requires additional study. The secondary evaluation of athletes with ECG abnormalities can vary by physician experience, ${ }^{72}$ and the recommended evaluation of specific ECG abnormalities should be more clearly defined. Finally, the extent to which technology advances and computerised ECG interpretation algorithms using modern athlete-specific standards will improve physician ECG interpretation accuracy is unknown and requires investigation.

\section{OUTCOMES FOR EARLY DETECTION OF CARDIOVASCULAR DISEASE}

Current assessment and knowledge gaps

Outcome studies of cardiovascular screening in athletes are limited and present conflicting evidence regarding the potential benefit to prevent SCA/D. ${ }^{35} 5196$ In addition, the natural history and absolute risk of conditions associated with SCA/D in athletes identified with a cardiac disorder during preparticipation screening is largely unknown with limited outcome-based evidence.

However, cardiovascular screening is supported based on the premise that early detection of pathological cardiac disorders is important and could make a positive difference, and diseasespecific data suggest that individualised risk stratification and management lowers mortality for some conditions. For example, large cohort studies using current management strategies and therapeutic measures have demonstrated improved survival with a low hypertrophic cardiomyopathy-related mortality in children and young adults with hypertrophic cardiomyopathy. ${ }^{97} 98$ A prospective study from Italy found a $73 \%$ mortality reduction in athletes from early detection of hypertrophic cardiomyopathy compared to unscreened non-athletes. ${ }^{51}$ In addition, individualised management and indepth counseling of children diagnosed with long QT syndrome have shown low cardiac event rates and no deaths in two separate cohorts of young recreational and competitive athletes. ${ }^{99} 100$ Expert consensus guidelines for risk stratification and management of asymptomatic athletes identified with a Wolff-Parkinson-White pattern also were developed in partnership between the Pediatric and Congenital Electrophysiology Society and the Heart Rhythm Society. ${ }^{101}{ }^{102}$ In addition, the American Heart Association and American College of Cardiology recently updated their "Eligibility and Disqualification Recommendations for Competitive Athletes with Cardiovascular Abnormalities." 103 The language and content in these guidelines affirms from cardiology experts that early detection of conditions at risk has the potential for individual benefit. ${ }^{103}$ Finally, the accurate diagnosis of an inherited cardiac condition in an individual athlete, and the appropriate guidance for participation and treatment, may benefit not only the individual athlete, but also the entire family and possibly future generations through appropriate genetic testing and counseling.

The question of whether early detection provides more benefit than harm applies to cardiovascular screening by any means and the potential risks associated with the early detection and therapeutic process. The detection of a cardiac condition associated with SCA/D statistically places an athlete in a higher risk category than an athlete without a cardiac condition detected by screening. However, data to quantify and predict individual risk are limited, and the potential harms of secondary testing of screening abnormalities must be considered.

Overdiagnosis refers to a disorder detected through screening that does not lead to symptoms or a major event. ${ }^{104-106}$ The potential for overdiagnosis can be a product of any cardiovascular screening strategy (ie, history and physical examination with or without ECG), but will increase when using modalities with a higher sensitivity. The number of athletes detected with conditions at potential risk needed to identify one athlete that will go on to have SCA/D is affected by the accuracy of the screening procedures, the predicted prevalence of disorders at elevated risk and the estimated incidence of SCA/D (table 3). The lack of 


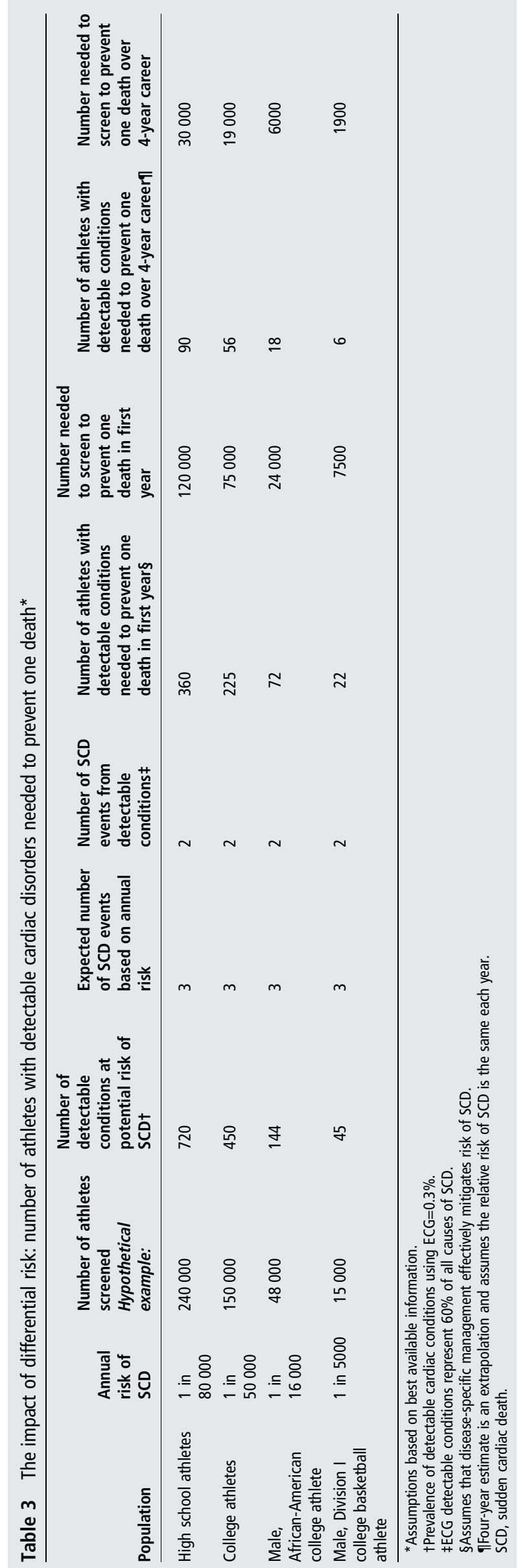

definitive outcome data and the uncertainty surrounding overdiagnosis complicate our understanding of whether the potential benefits of adding ECG to cardiovascular screening in athletes will outweigh the potential risks.

\section{PHYSICIAN RESOURCES AND INFRASTRUCTURE Current assessment}

An ECG screening programme requires physicians knowledgeable in current athlete-specific ECG interpretation standards and adequate cardiology resources to guide the secondary investigation of ECG abnormalities. The absence of a physician workforce capable of accurate ECG interpretation in athletes and the secondary evaluation of ECG abnormalities is a major obstacle to wider application of ECG screening, even among US universities and colleges. ${ }^{6} 107$

Sports medicine physicians conducting or considering ECG screening as a part of a PPE are strongly encouraged to establish a close and collaborative relationship with local cardiology resources as part of a cardiovascular care team approach. Some considerations when identifying appropriate cardiology resources include: specialist availability with practice models that facilitate rapid turn around times; access to timely diagnostic testing; familiarity with contemporary athlete-specific ECG interpretation criteria and a commitment to work in partnership following the establishment of an exercise or competitionlimiting diagnosis. The development of regional referral centres has also been proposed to assist in ECG interpretation and the evaluation of athletes with a suspected or known cardiovascular disorder when local expertise is not available. ${ }^{6}$

Likewise, cardiovascular screening strategies using a standard history and physical examination recommended for over two decades are still not uniformly implemented or practised. ${ }^{73-76}$ Additional education and implementation strategies regarding best practices for history and physical examination need to be pursued.

\section{Educational initiatives}

Consensus standards for ECG interpretation in athletes have evolved considerably over the past decade with each revised criteria set improving specificity. ${ }^{84-87}$ Online training modules are available at no cost to physicians to foster a common understanding of modern ECG interpretation standards (http:// learning.bmj.com/ECGathlete). This may serve as a starting point for physicians, although accurate ECG interpretation will be enhanced by additional clinical experience and ongoing education.

The PPE Monograph is available to guide a standardised preparticipation history and physical examination. ${ }^{1}$ Additional resources are also available to aid in Marfan's syndrome recognition and diagnosis (http://www.marfan.org/dx/home) and cardiac auscultation skills (http://www.easyauscultation.com/ heart-sounds).

\section{RECOMMENDATIONS \\ Moving forward: a new paradigm for cardiovascular screening in athletes}

While knowledge gaps exist between the available evidence and the evidence needed to precisely quantify and balance the potential benefits versus the potential harms associated with different models of cardiovascular screening, the lack of definitive data should not discourage reassessment of our current practices. The ECG screening debate is often framed as a choice between universal, mandatory screening or no screening at all. ${ }^{108}$ These polarised options provide little guidance to explore 
alternative strategies for the individual physician who recognises the limitations of the current PPE model, understands that adding an ECG has potential benefits and risks and recognises a lack of clear patient-oriented outcome evidence. The primary care sports medicine physician, however, is still responsible for the cardiovascular screening of the individual athlete and in many cases may guide decision-making for at risk populations. A new framework to guide sports medicine physicians in choosing how they perform cardiovascular screening is warranted (figure 1).

This AMSSM task force, in moving forward with this position statement and new paradigm, reviewed and reflected on guiding ethical principles and core concepts as applied to evidence-based medicine. The group acknowledged two key ethical principles that guide medical decision-making: beneficence and nonmaleficence. Ultimately, the benefit of any intervention must exceed the risks for the intervention to be ethical. In addition, while the physician functions as an educator in informing patients about benefits and risks, in the end it is the patient who assigns them weight. The task force additionally recognised that evidence-based medicine is "the conscientious, explicit and judicious use of current best evidence in making decisions about the care of the individual patient. It means integrating individual clinical expertise with the best available external clinical evidence from systematic research.”109 110 Thus, a context for clinical decision-making for cardiovascular screening must be developed that accounts for the individual skills and expertise of the physician, as well as the individual characteristics of the patient or patient population.

At this time, this task force recognises that there is not conclusive evidence to make a universal recommendation for or against the incorporation of ECG screening during the preparticipation evaluation. However, this task force additionally recognises that the current PPE has substantial limitations for detecting occult cardiac disorders, the ECG provides increased sensitivity for detecting some cardiac disorders, a discordance exists between the prevalence of cardiac disorders and the rate of SCA/D and evolving data support that some athletes are at considerably higher risk of SCA/D than others. Accordingly, the cornerstone of this document's recommendations is respect for the autonomy of individual physicians to assess the current evidence, evaluate their unique clinical situation and decide what they believe to be the best decision for their patient or patient population. In this scenario, it is understood that some physicians may decide to implement a strategy for cardiovascular screening that incorporates an ECG, while others may not. Any ECG screening programme if implemented, however, should

\section{Strength of Rationale for ECG Screening}

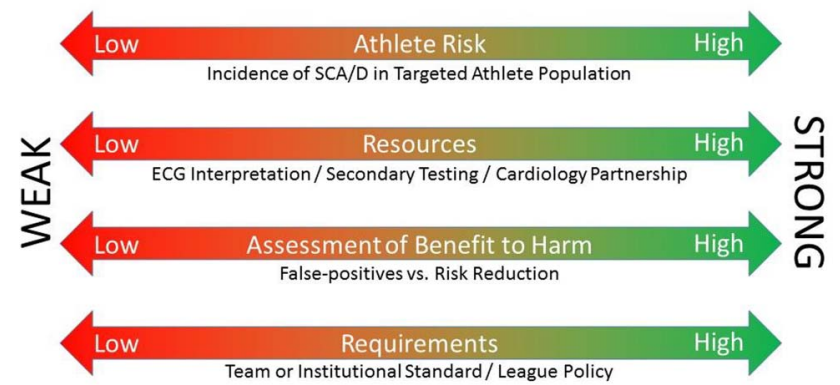

Figure 1 Major considerations and strength of rationale for electrocardiogram screening. SCA/D, sudden cardiac arrest/death. have a strong infrastructure, high quality control, and consider informed consent that outlines the potential benefits and risks with the athlete (and/or parent/guardian). Optimally, the decision to incorporate or exclude an ECG from the preparticipation evaluation is one of shared decision-making between a patient and a provider.

Risk, resources and opinion on early detection

Where does the risk/benefit ratio change so that adding an ECG is beneficial to the athlete? The primary considerations to add ECG include: (1) individual risk based on age, sex, race, sport and level of play; (2) physician expertise and available cardiology resources to conduct an ECG screening programme with high quality and (3) physician assessment that the utilisation of ECG for the individual athlete provides more benefit than harm (figure 1). Recognition of the differential risk in athletes may lead to an approach that more closely reflects individualised risk. For example, a physician may not add ECG for high school female athletes, but choose to use ECG screening in male, African-American college basketball players. Given the uncertainty and the desire to balance potential harms with the potential benefit of early detection, differential risk, as well as the availability of cardiology resources, may have a substantial impact on the risk/benefit ratio and thus the choice of screening strategy.

In centres where ECG screening is conducted by clinicians trained in athlete ECG interpretation using modern standards and with adequate cardiology resources for secondary investigations of ECG abnormalities, ECG screening can increase the detection of athletes potentially at risk for SCA/D with lower false-positive rates. However, this may not apply to sites with less experience or those without adequate cardiology infrastructure and support. A major challenge to adding ECG is improved training in athlete ECG interpretation and the presence of cardiology expertise for the secondary evaluation of ECG abnormalities.

The foundation of cardiovascular screening relies on the premise that early detection is important and prioritised. If one determines that early detection of occult cardiac disorders is of questionable benefit or outweighed by the potential risks of a particular screening strategy and the lack of definitive outcome data, then this stance argues for less screening or perhaps no screening. Some countries endorse a paradigm with no preparticipation cardiovascular screening of any sort. ${ }^{44} 111$

\section{Weighing the risks versus the benefits}

All screening risks the identification of disorders that may not become symptomatic or cause significant morbidity or mortality (overdiagnosis). If the threat (or evidence) of harms from early detection with potential overdiagnosis using a specific screening strategy is large, then screening by that means should be questioned.

The use of ECG will lead to increased detection and thus potentially a greater risk for overdiagnosis, misdiagnosis, unnecessary disqualification or even adverse events or outcomes from activity restrictions, medical management or evaluation and/or treatment procedures. In accepting an additional test to enhance the sensitivity of the PPE, one must also accept that the test layers on additional risk of harm through a greater number of false-positives, costly secondary investigations and the potential for unnecessary interventions, including temporary sports restriction and prohibiting exercise when not indicated. This added layer of risk may be magnified as the incidence of SCA/D declines. 
Identification of cardiovascular abnormalities also leads to opportunities for risk assessment and disease management. Published studies of ECG screening in relatively small US athlete cohorts have not reported major adverse events/harm or death as a result of screening. ${ }^{34} \quad 39-41 \quad 53707283$ Nonetheless, the potential risks and complications from invasive cardiovascular procedures and therapeutic interventions remain a valid concern. ${ }^{112} 113$ More outcome data are needed to define the procedural risk in athletes with conditions detected through screening. Screening by history and physical examination alone also has potential risks, such as false-positive responses requiring unnecessary investigations, a higher false-negative rate and perhaps false reassurance regarding cardiac safety.

\section{Physician autonomy}

The lack of clear outcome data at this time precludes an algorithmic or universal approach to the decision of adding an ECG to preparticipation screening. In addition, while this panel strongly supports the goals of the PPE and cardiovascular screening, in the absence of clear outcome-based evidence, legislative mandates requiring any particular cardiovascular screening strategy as obligatory, including history and physical examination with or without ECG, are unwarranted at this time. In the context of a developing evidence base, this panel respects the autonomy of physicians to choose the best strategy for the athlete population under their care. Physicians should be guided by the previously discussed considerations and their assessment of relevant and emerging research.

Sports medicine physicians responsible for the cardiovascular care of athletes they deem high risk for SCA/D should thoughtfully consider more intensive screening strategies, such as ECG screening. Until more definitive outcome data are available, maintaining the current standard of cardiovascular screening, without adding the ECG, is a reasonable choice for physicians caring for athletes. Some physicians, however, may favour the potential to prevent SCA/D in targeted risk groups and chose to add ECG screening in higher risk athlete populations. Some physicians interested in ECG screening may be limited by the lack of local cardiology resources and are unable to employ ECG screening programmes with sufficient quality control. And finally, physicians with extensive experience in ECG screening and robust cardiology resources may choose to include ECG for all of their athletes. A standardised questionnaire should be considered during the PPE and during well childcare visits that serve as the PPE to guide a comprehensive cardiac symptom and family history evaluation. Additional screening with an ECG should be considered if (and only if) accurate interpretation and proper cardiology resources can be developed or are currently available.

\section{The essential role of automated external defibrillators and emergency action plans}

No screening programme provides absolute protection against SCA/D. A proper emergency action plan and access to an automated external defibrillator (AED) are essential to improving outcomes from SCA in athletes. ${ }^{6} 13$ 114-116 Every school, club and organisation that sponsors athletic activities should be prepared to respond to a collapsed athlete with an acute cardiac emergency. An emergency action plan for SCA with written policies and procedures is recommended to ensure an efficient and structured response to a cardiac emergency. An emergency action plan for SCA including access to an AED increases the likelihood of bystander cardiopulmonary resuscitation, reduces the time to defibrillation and improves survival from SCA.
Successful programmes require an organised and practiced response, an established communication method to activate the emergency medical services system and rescuers trained and equipped to provide cardiopulmonary resuscitation and defibrillation.

Prompt recognition of SCA is the first step to an efficient emergency response. Resuscitation can be delayed because SCA is mistaken for a seizure or the rescuer misinterprets agonal gasping for normal breathing. ${ }^{13}{ }^{115}$ Coaches, sports medicine professionals and other anticipated first responders to SCA in an athlete must maintain a high index of suspicion for SCA in any collapsed and unresponsive athlete. The treatment of SCA involves immediate recognition and activation of the local emergency medical services system (ie, call 9-1-1), early cardiopulmonary resuscitation (starting with chest compressions) and prompt retrieval of an AED for defibrillation. AEDs should be strategically placed within schools and sporting facilities to achieve a collapse to first shock time of $<3 \mathrm{~min}$ (although immediate availability of AEDs is ideal). ${ }^{116} 117$

\section{FUTURE RESEARCH DIRECTIONS}

This panel has identified many knowledge gaps that would benefit from further investigation. However, the following research priorities are suggested:

1. Higher quality data on the aetiology of SCA/D in athletes to guide screening strategies. This requires standardised autopsies, wider application of postmortem genetic testing and review of the diagnosis in cases of SCA with survival.

2. The downstream impact of any screening programme requires more research, a better understanding of the natural history of cardiac disorders and more complete outcome data. The outcomes and clinical course of athletes identified with cardiovascular disorders at risk for SCA/D should be monitored inclusive of adverse events from diagnostic or therapeutic procedures, continued participation in sports and exercise as well as the occurrence of major cardiovascular events or other cardiovascular morbidity.

3. Potential avenues to refine the history and physical examination as a screening tool for cardiac disorders that place an athlete at elevated risk for SCA/D remain largely unexplored. Research efforts to improve the sensitivity, specificity and reliability of the history and physical examination are needed.

4. A potential gap exists between the quality and results of ECG screening at expert centres compared to the results of screening at more novice sites with less experience. More data addressing implementation research are needed to address the potential risks and benefits of ECG screening more broadly, and the potential impact of technology advances to assist accurate ECG interpretation results.

\section{CONCLUSIONS}

The primary goal of cardiovascular screening in competitive athletes is to detect cardiac disorders early in their natural history to more effectively mitigate the risk of SCA/D through improved risk stratification, targeted management and evidence-driven activity recommendations. Acknowledging the gaps and limitations of the history and physical examination, as well as those associated with the potential addition of ECG, to accomplish the goal of cardiovascular screening does not in itself endorse a particular strategy, but is fair to the current state of the science. ECG screening does offer enhanced detection of cardiac disorders at potential risk of $\mathrm{SCA} / \mathrm{D}$, but also increases the potential for false-positive results and the associated downstream 
consequences. In choosing a screening strategy, sports medicine physicians should consider and assess the differential risk of the athlete, the individual needs of their specific athlete population and community, their experience and available cardiology infrastructure as well as their evaluation of the risks and benefits of early detection as a means of reducing cardiovascular morbidity and mortality in athletes. ${ }^{118}$ No screening strategy provides absolute protection from $\mathrm{SCA} / \mathrm{D}$; therefore, proper emergency planning and prompt availability of AEDs during training and competition are critical. Widely practised and accepted screening standards are not perfect and should undergo continual revision as new data emerge. Accordingly, in the absence of a clear evidence-based strategy, AMSSM supports continued research in this area to validate the optimal strategies for reducing SCA/D in athletes. Finally, AMSSM respects and supports the autonomy of an individual sports medicine physician to assess the needs of their athlete population and the assets of their community to implement an appropriate screening strategy.

\section{Author affiliations \\ 'Department of Family Medicine, University of Washington, Seattle, Washington, USA \\ ${ }^{2}$ Department of Military and Emergency Medicine, Uniformed Services University of the Health Sciences, Bethesda, Maryland, USA \\ ${ }^{3}$ Department of Family Medicine, University of North Carolina, Greensboro, North Carolina, USA \\ ${ }^{4}$ Department of Health and Kinesiology, Georgia Southern University, Statesboro, Georgia, USA \\ ${ }^{5}$ Department of Family Medicine, University of South Carolina Greenville School of Medicine, Greenville, South Carolina, USA \\ ${ }^{6}$ Department of Family Medicine, Carolinas Healthcare System, Charlotte, North Carolina, USA \\ ${ }^{7}$ Departments of Orthopedic Surgery, Family and Community Medicine, and Pediatrics, University of Texas Southwestern Medical Center, Dallas, Texas, USA ${ }^{8}$ Departments of Pediatrics, Orthopedics and Rehabilitation, University of Wisconsin School of Medicine and Public Health, Madison, Wisconsin, USA \\ ${ }^{9}$ Department of Family Medicine and Community Health, University of Minnesota, Minneapolis, Minnesota, USA}

Twitter Follow Robert Dimeff at @Robert @dimeff

Acknowledgements The authors thank the AMSSM Board of Directors and the following individuals for their review of the statement prior to publication: Aaron Baggish, MD, Mats Borjesson, MD, PhD, Benjamin Levine, MD, Brian Hainline, MD, Richard Kovacs, MD, and Willem Meeuwisse, MD, PhD.

Disclaimer The opinions and assertions contained here are private views and are not to be construed as official or as reflecting the views of the Uniformed Services University of the Health Sciences, the US Army Medical Department or the Department of Defense at large.

Competing interests None declared. Please see online supplementary appendix 1 for a list of volunteer positions, board and other paffiliations.

Provenance and peer review Not commissioned; externally peer reviewed.

\section{REFERENCES}

1 American Academy of Family Physicians, American Academy of Pediatrics, American College of Sports Medicine, et al. Preparticipation physical evaluation. 4th edn. American Academy of Pediatrics, 2010.

2 Maron BJ, Friedman RA, Kligfield P, et al. Assessment of the 12-lead electrocardiogram as a screening test for detection of cardiovascular disease in healthy general populations of young people (12-25 years of age): a scientific statement from the American Heart Association and the American College of Cardiology. J Am Coll Cardiol 2014;64:1479-514.

3 Corrado D, Pelliccia A, Bjornstad HH, et al. Cardiovascular pre-participation screening of young competitive athletes for prevention of sudden death: proposal for a common European protocol. Consensus Statement of the Study Group of Sport Cardiology of the Working Group of Cardiac Rehabilitation and Exercise Physiology and the Working Group of Myocardial and Pericardial Diseases of the European Society of Cardiology. Eur Heart J 2005;26:516-24.

4 Dvorak J, Grimm K, Schmied C, et al. Development and implementation of a standardized precompetition medical assessment of international elite football players - 2006 FIFA World Cup Germany. Clin I Sport Med 2009;19:316-21.
5 Ljungqvist A, Jenoure P, Engebretsen L, et al. The International Olympic Committee (IOC) Consensus Statement on periodic health evaluation of elite athletes March 2009. Br J Sports Med 2009;43:631-43.

6 Hainline B, Drezner JA, Baggish A, et al. Interassociation consensus statement on cardiovascular care of college student-athletes. J Am Coll Cardiol 2016;67:2981-95.

7 Wingfield K, Matheson GO, Meeuwisse WH. Preparticipation evaluation: an evidence-based review. Clin J Sport Med 2004;14:109-22.

8 Maron BJ, Levine BD, Washington RL, et al. Eligibility and disqualification recommendations for competitive athletes with cardiovascular abnormalities: Task Force 2: preparticipation screening for cardiovascular disease in competitive athletes: a Scientific Statement From the American Heart Association and American College of Cardiology. J Am Coll Cardiol 2015;66:2356-61.

9 Van Camp SP, Bloor CM, Mueller FO, et al. Nontraumatic sports death in high school and college athletes. Med Sci Sports Exerc 1995;27:641-7.

10 Maron BJ, Gohman TE, Aeppli D. Prevalence of sudden cardiac death during competitive sports activities in Minnesota high school athletes. J Am Coll Cardiol 1998;32:1881-4.

11 Drezner JA, Rogers KJ, Zimmer RR, et al. Use of automated external defibrillators at NCAA division I universities. Med Sci Sports Exerc 2005;37:1487-92.

12 Maron BJ, Doerer JJ, Haas TS, et al. Sudden deaths in young competitive athletes: analysis of 1866 deaths in the United States, 1980-2006. Circulation 2009;119:1085-92.

13 Drezner JA, Rao AL, Heistand J, et al. Effectiveness of emergency response planning for sudden cardiac arrest in United States high schools with automated external defibrillators. Circulation 2009:120:518-25.

14 Harmon KG, Asif IM, Klossner D, et al. Incidence of sudden cardiac death in national collegiate athletic association athletes. Circulation 2011;123:1594-600.

15 Maron BJ, Haas TS, Ahluwalia A, et al. Incidence of cardiovascular sudden deaths in Minnesota high school athletes. Heart Rhythm 2013;10:374-7.

16 Roberts WO, Stovitz SD. Incidence of sudden cardiac death in Minnesota high school athletes 1993-2012 screened with a standardized pre-participation evaluation. J Am Coll Cardiol 2013;62:1298-301.

17 Maron BJ, Haas TS, Murphy CJ, et al. Incidence and causes of sudden death in U. S. college athletes. J Am Coll Cardiol 2014;63:1636-43.

18 Toresdahl BG, Rao AL, Harmon KG, et al. Incidence of sudden cardiac arrest in high school student athletes on school campus. Heart Rhythm 2014;11:1190-4.

19 Drezner JA, Harmon KG, Marek JC. Incidence of sudden cardiac arrest in Minnesota high school student athletes: the limitations of catastrophic insurance claims. J Am Coll Cardiol 2014;63:1455-6.

20 Harmon KG, Asif IM, Ellenbogen $R$, et al. The incidence of sudden cardiac arrest in United States high school athletes. Br J Sports Med 2014;48:605.

21 Harmon KG, Asif IM, Maleszewski JJ, et al. Incidence, cause, and comparative frequency of sudden cardiac death in national collegiate athletic association athletes: a decade in review. Circulation 2015;132:10-19.

22 Harmon KG, Drezner JA, Wilson MG, et al. Incidence of sudden cardiac death in athletes: a state-of-the-art review. Br J Sports Med 2014;48:1185-92.

23 Eckart RE, Scoville SL, Campbell CL, et al. Sudden death in young adults: a 25-year review of autopsies in military recruits. Ann Intern Med 2004;141:829-34.

24 Eckart RE, Shry EA, Burke AP, et al. Sudden death in young adults an autopsy-based series of a population undergoing active surveillance. J Am Coll Cardiol 2011;58:1254-61.

25 Farioli A, Christophi CA, Quarta CC, et al. Incidence of sudden cardiac death in a young active population. J Am Heart Assoc 2015:4:e001818.

26 Atkins DL, Everson-Stewart S, Sears GK, et al. Epidemiology and outcomes from out-of-hospital cardiac arrest in children: the Resuscitation Outcomes Consortium Epistry-Cardiac Arrest. Circulation 2009;119:1484-91.

27 Chugh SS, Reinier K, Balaii S, et al. Population-based analysis of sudden death in children: the Oregon Sudden Unexpected Death Study. Heart Rhythm 2009;6:1618-22.

28 Cooper WO, Habel LA, Sox CM, et al. ADHD drugs and serious cardiovascular events in children and young adults. N Engl J Med 2011;365:1896-904.

29 Meyer L, Stubbs B, Fahrenbruch C, et al. Incidence, causes, and survival trends from cardiovascular-related sudden cardiac arrest in children and young adults 0 to 35 years of age: a 30-year review. Circulation 2012;126:1363-72.

30 Maron BJ, Haas TS, Duncanson ER, et al. Comparison of the frequency of sudden cardiovascular deaths in young competitive athletes versus nonathletes: should we really screen only athletes? Am J Cardiol 2016;117:1339-41.

31 Maron BJ, Friedman RA, Caplan A. Ethics of preparticipation cardiovascular screening for athletes. Nat Rev Cardiol 2015:12:375-8.

32 Solberg EE, Borjesson M, Sharma S, et al. Sudden cardiac arrest in sports-need for uniform registration: a Position Paper from the Sport Cardiology Section of the European Association for Cardiovascular Prevention and Rehabilitation. Eur I Prev Cardiol 2016;23:657-67.

33 Maron BJ. Sudden death in young athletes. N Engl J Med 2003;349:1064-75.

34 Fuller CM, McNulty CM, Spring DA, et al. Prospective screening of 5,615 high school athletes for risk of sudden cardiac death. Med Sci Sports Exerc 1997;29:1131-8. 
35 Corrado D, Basso C, Pavei A, et al. Trends in sudden cardiovascular death in young competitive athletes after implementation of a preparticipation screening program. JAMA 2006;296:1593-601.

36 Wilson MG, Basavarajaiah S, Whyte GP, et al. Efficacy of personal symptom and family history questionnaires when screening for inherited cardiac pathologies: the role of electrocardiography. Br J Sports Med 2008;42:207-11.

37 Bessem B, Groot FP, Nieuwland W. The Lausanne recommendations: a Dutch experience. Br J Sports Med 2009;43:708-15.

38 Hevia AC, Fernandez MM, Palacio JM, et al. ECG as a part of the preparticipation screening programme: an old and still present international dilemma. $\mathrm{Br}$ J Sports Med 2011;45:776-9.

39 Baggish AL, Hutter AM Jr, Wang F, et al. Cardiovascular screening in college athletes with and without electrocardiography: a cross-sectional study. Ann Intern Med 2010;152:269-75.

40 Fudge J, Harmon KG, Owens DS, et al. Cardiovascular screening in adolescents and young adults: a prospective study comparing the Pre-participation Physical Evaluation Monograph 4th Edition and ECG. Br J Sports Med 2014;48:1172-8.

41 Drezner JA, Prutkin JM, Harmon KG, et al. Cardiovascular screening in college athletes. J Am Coll Cardiol 2015:65:2353-5.

42 Corrado D, Basso C, Rizzoli G, et al. Does sports activity enhance the risk of sudden death in adolescents and young adults? J Am Coll Cardiol 2003:42:1959-63.

43 de Noronha SV, Sharma S, Papadakis M, et al. Aetiology of sudden cardiac death in athletes in the United Kingdom: a pathological study. Heart 2009;95:1409-14.

44 Holst AG, Winkel BG, Theilade J, et al. Incidence and etiology of sports-related sudden cardiac death in Denmark-implications for preparticipation screening. Heart Rhythm 2010;7:1365-71.

45 Suarez-Mier MP, Aguilera B, Mosquera RM, et al. Pathology of sudden death during recreational sports in Spain. Forensic Sci Int 2013;226:188-96.

46 Ullal AJ, Abdelfattah RS, Ashley EA, et al. Hypertrophic cardiomyopathy as a cause of sudden cardiac death in the young: a meta-analysis. Am J Med 2016;129:486-96.e2.

47 Finocchiaro G, Papadakis M, Robertus JL, et al. Etiology of sudden death in sports: insights from a United Kingdom Regional Registry. J Am Coll Cardiol 2016:67:2108-15

48 Maron BJ. Hypertrophic cardiomyopathy. Lancet 1997;350:127-33.

49 Semsarian C, Ingles J, Maron MS, et al. New perspectives on the prevalence of hypertrophic cardiomyopathy. J Am Coll Cardiol 2015;65:1249-54.

50 Maron BJ, Gardin JM, Flack JM, et al. Prevalence of hypertrophic cardiomyopathy in a general population of young adults. Echocardiographic analysis of 4111 subjects in the CARDIA Study. Coronary Artery Risk Development in (Young) Adults. Circulation 1995;92:785-9.

51 Corrado D, Basso C, Schiavon M, et al. Screening for hypertrophic cardiomyopathy in young athletes. $N$ Engl J Med 1998;339:364-9.

52 Basavarajaiah S, Wilson M, Whyte G, et al. Prevalence of hypertrophic cardiomyopathy in highly trained athletes: relevance to pre-participation screening. J Am Coll Cardiol 2008;51:1033-9.

53 Malhotra R, West JJ, Dent J, et al. Cost and yield of adding electrocardiography to history and physical in screening Division I intercollegiate athletes: a 5-year experience. Heart Rhythm 2011;8:721-7.

54 Harmon KG, Zigman M, Drezner JA. The effectiveness of screening history, physical exam, and ECG to detect potentially lethal cardiac disorders in athletes: a systematic review/meta-analysis. J Electrocardio/ 2015;48:329-38.

55 Corrado D, Basso C, Thiene G. Sudden cardiac death in young people with apparently normal heart. Cardiovasc Res 2001:50:399-408.

56 Puranik R, Chow CK, Duflou JA, et al. Sudden death in the young. Heart Rhythm 2005:2:1277-82

57 Papadakis M, Sharma S, Cox S, et al. The magnitude of sudden cardiac death in the young: a death certificate-based review in England and Wales. Europace 2009;11:1353-8.

58 Solberg EE, Gjertsen F, Haugstad E, et al. Sudden death in sports among young adults in Norway. Eur J Cardiovasc Prev Rehabil 2010;17:337-41.

59 Margey R, Roy A, Tobin S, et al. Sudden cardiac death in 14- to 35-year olds in Ireland from 2005 to 2007: a retrospective registry. Europace 2011;13:1411-18.

60 Tester DJ, Ackerman MJ. The role of molecular autopsy in unexplained sudden cardiac death. Curr Opin Cardiol 2006;21:166-72.

61 Tester DJ, Medeiros-Domingo A, Will ML, et al. Cardiac channel molecular autopsy: insights from 173 consecutive cases of autopsy-negative sudden unexplained death referred for postmortem genetic testing. Mayo Clin Proc 2012;87:524-39

62 Maron BJ, Thompson PD, Puffer JC, et al. Cardiovascular preparticipation screening of competitive athletes. A statement for health professionals from the Sudden Death Committee (clinical cardiology) and Congenital Cardiac Defects Committee (cardiovascular disease in the young), American Heart Association. Circulation 1996:94:850-6.

63 Maron BJ, Thompson PD, Ackerman MJ, et al. Recommendations and considerations related to preparticipation screening for cardiovascular abnormalities in competitive athletes: 2007 update: a scientific statement from the American
Heart Association Council on Nutrition, Physical Activity, and Metabolism: endorsed by the American College of Cardiology Foundation. Circulation 2007;115:1643-55.

64 Weiner RB, Wang F, Isaacs SK, et al. Blood pressure and left ventricular hypertrophy during American-style football participation. Circulation 2013;128:524-31.

65 Stiefel EC, Field L, Replogle W, et al. The prevalence of obesity and elevated blood pressure in adolescent student athletes from the state of Mississippi. Orthop J Sports Med 2016;4:1-9.

66 Black HR, Sica D, Ferdinand K, et al. Eligibility and disqualification recommendations for competitive athletes with cardiovascular abnormalities: task force 6: hypertension: a scientific statement from the American Heart Association and the American College of Cardiology. J Am Coll Cardiol 2015;66:2393-7.

67 Maron BJ, Shirani J, Poliac LC, et al. Sudden death in young competitive athletes. Clinical, demographic, and pathological profiles. JAMA 1996;276:199-204.

68 Alapati S, Strobel N, Hashmi S, et al. Sudden unexplained cardiac arrest in apparently healthy children: a single-center experience. Pediatr Cardiol 2013;34:639-45.

69 Sealy DP, Pekarek L, Russ D, et al. Vital signs and demographics in the preparticipation sports exam: do they help us find the elusive athlete at risk for sudden cardiac death? Curr Sports Med Rep 2010;9:338-41.

70 Price DE, McWilliams A, Asif IM, et al. Electrocardiography-inclusive screening strategies for detection of cardiovascular abnormalities in high school athletes. Heart Rhythm 2014;11:442-9.

71 Dunn TP, Pickham D, Aggarwal S, et al. Limitations of current AHA guidelines and proposal of new guidelines for the preparticipation examination of athletes. Clin J Sport Med 2015;25:472-7.

72 Drezner JA, Owens DS, Prutkin JM, et al. Electrocardiographic screening in National Collegiate Athletic Association Athletes. Am J Cardio 2016:118:754-9.

73 Madsen NL, Drezner JA, Salerno JC. Sudden cardiac death screening in adolescent athletes: an evaluation of compliance with national guidelines. Br J Sports Med 2013:47:172-7.

74 Madsen NL, Drezner JA, Salerno JC. The preparticipation physical evaluation: an analysis of clinical practice. Clin J Sport Med 2014;24:142-9.

75 Charboneau ML, Mencias T, Hoch AZ. Cardiovascular screening practices in collegiate student-athletes. PM R 2014;6:583-6; quiz 6.

76 Caswell SV, Cortes N, Chabolla M, et al. State-specific differences in school sports preparticipation physical evaluation policies. Pediatrics 2015;135:26-32.

77 Kumar K, Thompson WR. Evaluation of cardiac auscultation skills in pediatric residents. Clin Pediatr (Phila) 2013;52:66-73.

78 Sztajzel JM, Picard-Kossovsky M, Lerch R, et al. Accuracy of cardiac auscultation in the era of Doppler-echocardiography: a comparison between cardiologists and internists. Int J Cardiol 2010;138:308-10.

79 Dhuper S, Vashist S, Shah N, et al. Improvement of cardiac auscultation skills in pediatric residents with training. Clin Pediatr (Phila) 2007:46:236-40.

80 Vukanovic-Criley JM, Criley S, Warde CM, et al. Competency in cardiac examination skills in medical students, trainees, physicians, and faculty: a multicenter study. Arch Intern Med 2006;166:610-16.

81 O'Connor FG, Johnson JD, Chapin M, et al. A pilot study of clinical agreement in cardiovascular preparticipation examinations: how good is the standard of care? Clin J Sport Med 2005;15:177-9.

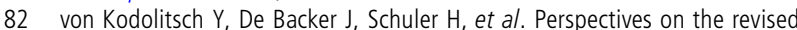
Ghent criteria for the diagnosis of Marfan syndrome. App/ Clin Genet 2015:8:137-55.

83 Fuller C, Scott C, Hug-English C, et al. Five-year experience with screening electrocardiograms in National Collegiate Athletic Association Division I Athletes. Clin J Sport Med 2016;26:369-75.

84 Sheikh N, Papadakis M, Ghani S, et al. Comparison of electrocardiographic criteria for the detection of cardiac abnormalities in elite black and white athletes. Circulation 2014:129:1637-49.

85 Brosnan M, La Gerche A, Kalman J, et al. The Seattle Criteria increase the specificity of preparticipation ECG screening among elite athletes. Br J Sports Med 2014:48:1144-50.

86 Riding NR, Sheikh N, Adamuz C, et al. Comparison of three current sets of electrocardiographic interpretation criteria for use in screening athletes. Heart 2014;101:384-90

87 Pickham D, Zarafshar S, Sani D, et al. Comparison of three ECG criteria for athlete pre-participation screening. J Electrocardiol 2014;47:769-74.

88 Marek J, Bufalino V, Davis J, et al. Feasibility and findings of large-scale electrocardiographic screening in young adults: data from 32,561 subjects. Heart Rhythm 2011:8:1555-9.

89 Drezner JA, Asif IM, Owens DS, et al. Accuracy of ECG interpretation in competitive athletes: the impact of using standised ECG criteria. Br J Sports Med 2012:46:335-40.

90 Exeter DJ, Elley CR, Fulcher ML, et al. Standardised criteria improve accuracy of ECG interpretation in competitive athletes: a randomised controlled trial. $\mathrm{Br}$ J Sports Med 2014;48:1167-71. 
91 Magee C, Kazman J, Haigney M, et al. Reliability and validity of clinician ECG interpretation for athletes. Ann Noninvasive Electrocardiol 2014;19:319-29.

92 Brosnan M, La Gerche A, Kumar S, et al. Modest agreement in ECG interpretation limits the application of ECG screening in young athletes. Heart Rhythm 2015; 12:130-6

93 Hill AC, Miyake CY, Grady S, et al. Accuracy of interpretation of preparticipation screening electrocardiograms. J Pediatr 2011;159:783-8.

94 Kligfield P, Gettes LS, Bailey JJ, et al. Recommendations for the standardization and interpretation of the electrocardiogram: part I: the electrocardiogram and its technology a scientific statement from the American Heart Association Electrocardiography and Arrhythmias Committee, Council on Clinical Cardiology; the American College of Cardiology Foundation; and the Heart Rhythm Society endorsed by the International Society for Computerized Electrocardiology. J Am Coll Cardiol 2007;49:1109-27.

95 Asplund CA, Asif IM. Cardiovascular preparticipation screening practices of college team physicians. Clin J Sport Med 2014;24:275-9.

96 Steinvil A, Chundadze T, Zeltser D, et al. Mandatory electrocardiographic screening of athletes to reduce their risk for sudden death proven fact or wishful thinking? J Am Coll Cardiol 2011:57:1291-6.

97 Maron BJ, Rowin EJ, Casey SA, et al. Hypertrophic cardiomyopathy in children, adolescents, and young adults associated with low cardiovascular mortality with contemporary management strategies. Circulation 2016;133:62-73.

98 Maron BJ, Maron MS. Contemporary strategies for risk stratification and prevention of sudden death with the implantable defibrillator in hypertrophic cardiomyopathy. Heart Rhythm 2016;13:1155-65.

99 Johnson JN, Ackerman MJ. Return to play? Athletes with congenital long QT syndrome. Br J Sports Med 2013;47:28-33.

100 Aziz PF, Sweeten T, Vogel RL, et al. Sports participation in genotype positive children with long QT syndrome. JACC Clin Electrophysiol 2015;1:62-70.

101 Cohen MI, Triedman JK, Cannon BC, et al. PACES/HRS expert consensus statement on the management of the asymptomatic young patient with a Wolff-Parkinson-White (WPW, ventricular preexcitation) electrocardiographic pattern: developed in partnership between the Pediatric and Congenital Electrophysiology Society (PACES) and the Heart Rhythm Society (HRS). Endorsed by the governing bodies of PACES, HRS, the American College of Cardiology Foundation (ACCF), the American Heart Association (AHA), the American Academy of Pediatrics (AAP), and the Canadian Heart Rhythm Society (CHRS). Heart Rhythm 2012;9:1006-24.

102 Al-Khatib SM, Arshad A, Balk EM, et al. Risk stratification for arrhythmic events in patients with asymptomatic pre-excitation: a systematic review for the $2015 \mathrm{ACC} /$ AHA/HRS Guideline for the Management of Adult Patients With Supraventricular Tachycardia: a report of the American College of Cardiology/American Heart Association Task Force on Clinical Practice Guidelines and the Heart Rhythm Society. Circulation 2016;133:e575-86.
103 Maron BJ, Zipes DP, Kovacs RJ. Eligibility and disqualification recommendations for competitive athletes with cardiovascular abnormalities: preamble, principles, and general considerations: a scientific statement from the American Heart Association and American College of Cardiology. J Am Coll Cardiol 2015;66:2343-9.

104 Oeffinger KC, Fontham ET, Etzioni R, et al. Breast cancer screening for women at average risk: 2015 guideline update from the American Cancer Society. JAMA 2015;314:1599-614.

105 Myers ER, Moorman P, Gierisch JM, et al. Benefits and harms of breast cancer screening: a systematic review. JAMA 2015;314:1615-34.

106 Keating NL, Pace LE. New guidelines for breast cancer screening in US women. JAMA 2015;314:1569-71.

107 Drezner JA. ECG screening in athletes: time to develop infrastructure. Heart Rhythm 2011;8:1560-1.

108 Drezner JA, Levine BD, Vetter VL. Reframing the debate: screening athletes to prevent sudden cardiac death. Heart Rhythm 2013;10:454-5.

109 Evidence-Based Medicine Working Group. Evidence-based medicine. A new approach to teaching the practice of medicine. JAMA 1992;268:2420-5.

110 Sackett D. Evidence-based medicine. Lancet 1995;346:1171.

111 Risgaard B, Tfelt-Hansen J, Winkel BG. Sports-related sudden cardiac death: how to prove an effect of preparticipation screening? Heart Rhythm 2016;13:1560-2.

112 Olde Nordkamp LR, Postema PG, Knops RE, et al. Implantable cardioverter-defibrillator harm in young patients with inherited arrhythmia syndromes: a systematic review and meta-analysis of inappropriate shocks and complications. Heart Rhythm 2016;13:443-54.

113 Hamilton RM. Implantable devices in young patients: hitting the reset button on risk versus benefit. Heart Rhythm 2016;13:455-6.

114 Drezner JA, Courson RW, Roberts WO, et al. Inter-association task force recommendations on emergency preparedness and management of sudden cardiac arrest in high school and college athletic programs: a consensus statement. Clin J Sport Med 2007;17:87-103.

115 Drezner JA, Toresdahl BG, Rao AL, et al. Outcomes from sudden cardiac arrest in US high schools: a 2-year prospective study from the National Registry for AED Use in Sports. Br J Sports Med 2013:47:1179-83.

116 Casa DJ, Almquist J, Anderson SA, et al. The inter-association task force for preventing sudden death in secondary school athletics programs: best-practices recommendations. J Athl Train 2013;48:546-53.

117 Dvorak J, Kramer EB, Schmied CM, et al. The FIFA medical emergency bag and FIFA 11 steps to prevent sudden cardiac death: setting a global standard and promoting consistent football field emergency care. Br J Sports Med 2013;47:1199-202.

118 Drezner JA, O'Connor FG, Harmon KG, et al. Infographic: AMSSM position statement on cardiovascular preparticipation screening in athletes: current evidence, knowledge gaps, recommendations and future directions. Br J Sports Med 2017:51:169. 


\section{Correction: AMSSM position statement on cardiovascular preparticipation screening in athletes: current evidence, knowledge gaps, recommendations and future directions}

Drezner JA, O'Connor FG, Harmon KG, et al. AMSSM position statement on cardiovascular preparticipation screening in athletes: current evidence, knowledge gaps, recommendations and future directions. Br J Sports Med 2017;51:153-67

This article has been co-published in the Clinical Journal of Sport Medicine, and Current Sports Medicine Reports.

(C) Article author(s) (or their employer(s) unless otherwise stated in the text of the article) 2018. All rights reserved. No commercial use is permitted unless otherwise expressly granted.

Br J Sports Med 2018;52:600. doi:10.1136/bjsports-2016-096781corr1

D) Check for updates

\section{REFERENCES}

1 Drezner JA, O'Connor FG, Harmon KG, et al. AMSSM position statement on cardiovascular preparticipation screening in athletes: current evidence, knowledge gaps. Recommendations and Future Directions 2016;26:347-61.

2 Drezner JA, O'Connor FG, Harmon KG, et al. AMSSM position statement on cardiovascular preparticipation screening in athletes: current evidence, knowledge gaps, recommendations and future directions. Curr Sports Med Rep 2016;15:359-75. 